\title{
OLHANDO A CRIANÇA E SEUS OUTROS: UMA TRAJETÓRIA DE PESQUISA EM EDUCAÇÃO INFANTIL ${ }^{12}$
}

\author{
Maria Clotilde Rossetti-Ferreira \\ Katia de Souza Amorim \\ Zilma de Moraes Ramos de Oliveira
}

Resumo: Com o objetivo de contribuir para o atual e intenso processo de revisão de concepções e de seleção e fortalecimento de práticas pedagógicas mediadoras da aprendizagem e desenvolvimento das crianças em creches e pré-escolas, e com base nas experiências de pesquisa do CINDEDI, abordamos neste artigo uma série de questões que nos parecem relevantes para a compreensão desse fenômeno da educação coletiva de bebês. Que contribuições as pesquisas sobre o desenvolvimento humano têm a oferecer para essa discussão? De que concepção de desenvolvimento elas partem? Que perspectiva metodológica pode abrir caminhos promissores para se compreender as formas das crianças e seus educadores atuarem e se modificarem com a experiência? Como entender as noções de estágios de desenvolvimento, a função do professor na aprendizagem, os fatores explicativos do desenvolvimento infantil e a avaliação do desenvolvimento nessa faixa etária? Tanto os familiares como os profissionais da creche interagem com a criança e organizam seu ambiente conforme suas expectativas sobre o seu desenvolvimento e sobre seu próprio papel em relação a ela.Tais expectativas são adquiridas através de suas experiências de vida naquela cultura. Várias expectativas, crenças e teorias psicológicas

1 Este artigo foi reformulado a partir de uma conferência de abertura de evento da Sociedade Brasileira de Psicologia do Desenvolvimento (SBPD), proferida pela primeira autora, cuja referência de publicação vem a seguir: Rossetti-Ferreira, M. C.(2006). Olhando a pessoa e seus outros, de perto e de longe, no antes, aqui e depois. In D. Colinvaux, L.B. Leite \& D.D.Dell'Aglio (Orgs) Psicologia do desenvolvimento: teorias e pesquisas e aplicações (pp. 19-59). São Paulo: Casa do Psicólogo.

2 As autoras agradecem os auxílios e bolsas do Conselho Nacional de Desenvolvimento Científico e Tecnológico (CNPq), Fundação de Auxílio à Pesquisa do Estado de São Paulo (FAPESP) e Coordenação de Aperfeiçoamento de Pessoal de Nível Superior (CAPES), que possibilitaram suas pesquisas. 
têm, assim, um forte poder auto-realizador, ajudando a construir competências e deficiências. Sem dúvida, as crianças e as equipes de educadores das instituições de Educação Infantil têm muito a ganhar conforme repensam essas questões.

Palavras-chave: Educação infantil. Concepções sobre desenvolvimento. Interação criança-criança. Rede de significações.

A área de educação infantil vive hoje intenso processo de revisão de concepções e de seleção e fortalecimento de práticas pedagógicas mediadoras da aprendizagem e desenvolvimento das crianças em creches e préescolas. Em particular, a discussão sobre como orientar o trabalho junto às crianças de até três anos em creches tem se mostrado prioritária. Essa temática apenas agora começa a ser tratada em cursos de formação de professores e os conhecimentos neles trabalhados necessitam responder a várias questões, como: Que contribuições as pesquisas sobre o desenvolvimento humano têm a oferecer à educação de bebês em creches? De que concepção de desenvolvimento elas partem? Que perspectiva metodológica pode abrir caminhos promissores para se compreender as formas das crianças e seus educadores atuarem e se modificarem com a experiência? Como entender as noções de maturação, de estágios de desenvolvimento, a função do professor na aprendizagem, os fatores explicativos do desenvolvimento infantil e a avaliação desse desenvolvimento?

Visões teórico-metodológicas contribuem para construir realidades sociais que podem, por sua vez, influir, modificar e ampliar/restringir o desenvolvimento e a qualidade de vida das pessoas, podendo muitas vezes até inseri-las em um movimento de exclusão. As teorias, em função de seus pressupostos, consolidam formas não só de compreender e estudar os processos desenvolvimentais, como também elas constituem as relações que Ihes darão suporte e as práticas profissionais que incidirão sobre elas. Isso chama a atenção para a responsabilidade moral e ética do pesquisador.

Em função dessas questões, ao longo de quase três décadas, no CINDEDI, temos investigado vários temas sobre educação infantil coletiva, de uma forma articulada com a participação em discussões e proposições de políticas e práticas sociais na/para a área. Ao longo desse período, construímos uma perspectiva teórico-metodológica que nos tem possibilitado compreender e orientar formas de educação e cuidado de crianças pequenas em instituições, como é o caso da creche, da pré-escola e de abrigos.

Entendemos o desenvolvimento humano como um "processo que envolve coconstrução nas e através das interações que as pessoas estabelecem em cenários específicos, os quais são socialmente regulados e culturalmente organizados". (Amorim, 2002, p. 2). De uma perspectiva sócio- 
histórica, tal processo se dá pela imersão das pessoas em práticas culturais onde atuam a partir de posições historicamente construídas em relação a seus parceiros (Oliveira, 2002).

Essas concepções serviram de base para a perspectiva teórico-metodológica de análise dos comportamentos e do desenvolvimento humano por nós elaborada, denominada Rede de Significações (RedSig) (RossettiFerreira, Amorim, \& Silva, 2004). Ela estuda o desenvolvimento humano dentro de uma abordagem que contempla o paradigma da complexidade e possibilita que o foco de análise de uma situação ou proposta se coloque nas interações que as pessoas estabelecem, em contextos concretos, e que são permeadas por uma matriz sócio-histórica e por significações que têm materialidade no aqui e agora das situações.

Nossa contribuição aqui será a de mostrar como aquela perspectiva abre novos olhares para a educação e o desenvolvimento de crianças de até três anos. Para tanto, vamos inicialmente fazer algumas considerações e dialogar com algumas linhas da Psicologia do Desenvolvimento.

\section{O foco no indivíduo/pessoa}

Ao propor sua teoria ecológica de desenvolvimento humano, Urie Bronfenbrenner $(1979,1986)$ apontou, a partir de extensa revisão bibliográfica, que tem predominado na Psicologia do Desenvolvimento o estudo dos processos de desenvolvimento com foco no indivíduo (geralmente na criança). O foco na díade adulto-criança teria surgido posteriormente, sendo priorizada a díade mãe-criança. Apesar das intensas mudanças ocorridas desde o levantamento de Bronfenbrenner, outras análises revelaram que esses focos continuam a prevalecer nas investigações e intervenções dos psicólogos (Cairns, 1983; Horowitz, 1987).

A maioria dos Manuais de Psicologia do Desenvolvimento reflete bem a predominância de uma visão fragmentada e descontextualizada na área. Fala-se no desenvolvimento linear do indivíduo, agrupando os fatos de tal processo em estágios, etapas ou fases. No entanto, vale destacar que entre os diferentes autores que têm trabalhado com a concepção de estágios e fases, há diferenças importantes, traduzindo concepções de estágios muito diversas e até mesmo opostas. Apesar disso, os autores esforçam-se por definir os estágios e sua sucessão; por discutir o problema da passagem de um estágio a outro e, ainda, por colocar a questão sobre a continuidade/descontinuidade do desenvolvimento. Como frisa Horowitz (1987), três têm sido as características centrais da busca por sedimentar essa linha: 1) apesar das aparentes amplas variações nos ambientes nos quais as crianças crescem e se desenvolvem, há uma grande correspondência entre crianças normais com respeito a comportamentos e capacidades gerais; 2 ) o surgimento e transformação daquelas habilidades são vistas como tendendo a 
ocorrer ao longo de um plano e de uma sequência muito semelhantes na maioria das crianças; e, 3) há uma tendência a que os desvios e deflexões do curso normal de desenvolvimento sejam curtos e de influência temporária com respeito à trajetória desenvolvimental.

Outro aspecto marcante nessa linha é de que, até cerca de duas décadas atrás, esse desenvolvimento e suas fases incluía apenas a infância, a idade escolar e a adolescência. Após essas fases, compreendia-se que era atingida a maturidade, à qual se seguia o declínio, a decadência, tanto que a área por muito tempo foi denominada de Psicologia da Criança. No entanto, a pressão do crescimento demográfico da população idosa nos países de primeiro mundo impôs uma revisão desses conceitos (como em Baltes, Staudinger \& Lindenberger, 1999), já prenunciada por autores como Jung e Erikson, passando-se a incluir os indivíduos na idade adulta e velhice como seres em desenvolvimento.

Em anos recentes, no entanto, a perspectiva de estágios tem sofrido uma série de questionamentos, como discute Horowitz (1987). Uma das críticas refere-se ao fato de que as sequências relativamente estáveis relacionadas à inteligência e ao desenvolvimento da linguagem têm sido identificadas em um número limitado de crianças. A maior evidência de sequência tem sido mais claramente observada no desenvolvimento motor. No entanto, apesar da sequência ser um critério necessário para o estabelecimento de estágios, em si ela não seria um critério suficiente.

Como diz a autora, embora não haja dúvidas de que existe uma ordem sequencial, permanecem, todavia, vários questionamentos. Os estágios, apesar de darem a aparência de um progresso na organização comportamental, não representam um recurso teoricamente simplificador, já que, como conceitos organizacionais, eles não permitem que se diga qualquer coisa sobre a natureza dos fatores que delimitam e/ou impulsionam o desenvolvimento comportamental humano.

Esse posicionamento, no entanto, não implica que não se considere os aspectos evolutivos e filogenéticos, mas que se deva olhar para eles, considerando-se as especificidades que têm no ser humano. Nesse sentido, Horowitz (1987) refere que o desenvolvimento comportamental humano através de elementos de organização de estágios dentro da história evolucionária teria se rompido e se dispersado no repertório comportamental no curso da evolução, deixando como dominante uma maior plasticidade comportamental, que é vantajosa para a sobrevivência humana.

De acordo com Maturana (1994) e Maturana e Varela (1984), embora a constituição genética, a anatomia e a fisiologia sejam humanas, o aspecto orgânico por si não é capaz de estabelecer as sequências e os percursos de desenvolvimento e, muito menos, de humanizar o bebê a partir do nascimento. $\mathrm{O}$ que se coloca é a necessidade de compreender o lugar do "outro social", ou seja, os diferentes parceiros da criança, adultos ou outras crianças, não como elemento que pode modificar o curso e percurso do 
desenvolvimento geneticamente programado, mas como inerentemente constituindo aquele desenvolvimento, a partir de uma intrínseca interação pessoa-meio. Isso traz à Psicologia do Desenvolvimento a necessidade de incorporar a noção de que, para que o desenvolvimento promova a humanização, o aspecto biológico deva ser considerado de maneira integrada com os aspectos relacional, contextual e cultural.

Nesse sentido, como discute Pino (2003), compreender o desenvolvimento psíquico como desenvolvimento cultural não se trata de mera questão terminológica, mas fundamentalmente epistemológica, a qual, em relação à tradição psicológica, representa certamente um novo paradigma.

Muitos autores têm buscado incorporar o outro e o contexto nos estudos e práxis da área. No entanto, numa abordagem simplista, tem prevalecido a visão de que as outras pessoas e o contexto são influências ou "variáveis" que podem vir a modular o processo de desenvolvimento da pessoa. Os estágios podem ser adiantados ou atrasados de acordo com o ambiente cultural ou educacional da criança. Mas, nessa perspectiva, o próprio fato de que os estágios parecem seguir a mesma ordem sequencial é suficiente para mostrar que o ambiente social não pode ser o responsável pelo processo. As influências só podem ter efeito se o sujeito é capaz de assimilá-las e ele só pode fazer isso se já possui os instrumentos ou estruturas adequadas.

Ainda, a plena acepção de ciclo vital, enquanto um conjunto de pessoas que se desenvolve reciprocamente emergiu pouco a pouco, tendo sido reforçada pelas teorias sistêmicas de família (Hinde, 1997). Tais visões buscam romper com aquela visão naturalizada do desenvolvimento e, através de uma visão sistêmica, o desenvolvimento de cada pessoa é visto em sua relação com as outras com quem convive. Discute-se assim que, ao nascer uma criança, nascem e se desenvolvem também uma mãe, um pai, uma avó, um tio ou irmão. A saída dos filhos de casa para irem estudar fora, em geral, após um período de crise, promove novo desenvolvimento não só nos filhos, mas também na mãe, que poderia ter se sentido destituída do papel de cuidar dos filhos e ter passado a se questionar sobre qual será sua identidade dali para frente. Essa crise pode atingir também o pai e ser modificada pela presença de outros filhos ou de avós em outras fases de desenvolvimento, com demandas e necessidades desenvolvimentais diversas. O casamento ou a maternidade ou paternidade da filha ou do filho irão encontrar a família em outro momento de desenvolvimento, estimulando processos de desenvolvimento em todos os participantes. No entanto, apesar da complexidade e dinâmica que tais perspectivas permitem apreender dos processos de desenvolvimento, elas ainda permanecem fora da maioria dos manuais e, provavelmente, da mentalidade de muitos psicólogos. 
Outro aspecto presente nas tradicionais formas de compreender os processos desenvolvimentais é o que os manuais revelam ao subdividirem as áreas de desenvolvimento em desenvolvimento motor, cognitivo, afetivo, social, moral. O que se verifica é uma fragmentação que dificulta apreender o indivíduo concreto em desenvolvimento através de ações e interações situadas em determinados contextos.

As avaliações do desenvolvimento da criança refletem essa visão, focando seu desempenho em situações controladas, seja em escalas de desenvolvimento ou em testes, como o da Situação Estranha (Ainsworth, Blehar, Waters, \& Wall, 1978). Esse último, particularmente, propõe-se a avaliar a relação de apego da criança com relação à mãe, mas ao fazê-lo focaliza apenas o comportamento da criança em uma situação artificial de exacerbação das respostas de apego. Analisa-se, assim, através do desempenho da criança nessas situações de avaliação, o suposto produto de um processo de desenvolvimento no qual grande parte da responsabilidade é atribuída à mãe. Entendemos que tais estudos implicam, como refere Bronfenbrenner (1977), uma ciência do comportamento estranho de crianças, em situações estranhas, com adultos estranhos, por períodos os mais curtos possíveis de tempo.

Apesar dessa questão, é muito frequente que programas de formação ou de avaliação curricular coloquem a avaliação da qualidade do trabalho pedagógico no produto desse trabalho a ser acessado a partir do comportamento das crianças. Como se trata dos primeiros anos de vida, as avaliações propostas em geral se fundamentam em escalas de desenvolvimento construídas pela psicologia, classificando as crianças conforme seu desempenho em itens referentes a habilidades motoras, de linguagem, de cuidado pessoal, de relacionamento social. Isso ocorre, muitas vezes, nas creches e pré-escolas. Contudo, diversas pesquisas têm mostrado haver baixa correlação entre um maior desenvolvimento ou sucesso posterior e um desenvolvimento mais precoce ou tardio (dentro da extensa amplitude de variação normal), seja da fala, da marcha, do controle de esfíncteres ou da sociabilidade com adultos ou crianças. O mais importante, entretanto, é o de que há uma constituição recíproca da pessoa em desenvolvimento e de seus contextos. Não seria, pois, mais interessante propor que fossem consideradas as necessidades desenvolvimentais das crianças e se avaliasse as condições de desenvolvimento que lhes estavam sendo oferecidas na e pela creche ou pré-escola e suas professoras?

Avaliar o quanto um contexto estaria propiciando explorações e interações diversificadas, em um ambiente estimulante e seguro, poderia orientar melhor os professores sobre como aperfeiçoar seu próprio trabaIho com as crianças e suas famílias. Além disso, os resultados da avaliação dão à família ou à escola/creche elementos que, muitas vezes, auxiliam a constituir a criança como competente ou deficiente, favorecendo sérios processos de exclusão. 
Nossa experiência sobre a inclusão de crianças com Paralisia Cerebral na escola regular (Yazlle, Amorim, \& Rossetti-Ferreira, 2004) e uma dissertação de mestrado sobre discursos de profissionais de saúde sobre os processos de inclusão social e escolar de crianças com Paralisia Cerebral (Roriz, 2005) evidenciaram claramente esses processos de exclusão em ação, tendo, como consequência, a construção social daquela deficiência prognosticada. $\mathrm{O}$ que os profissionais de saúde (incluindo-se aqui psicólogos e professores) falam para a família ao diagnosticarem algum tipo de problema na criança influencia fortemente as interações que os pais e familiares estabelecem com ela, tendo um grande efeito sobre as condições de cuidados e, consequentemente, de desenvolvimento que serão propiciadas a essa criança (Roriz, Amorim, \& Rossetti-Ferreira, 2005).

Uma família atendida por Lier de Vitto (1987) ${ }^{3}$,em consultório de fonoaudiologia, teve três crianças com sérias deficiências auditivas. No caso da primeira, a surdez só foi descoberta quando a criança tinha um ano e meio; na segunda, a descoberta se deu aos oito meses; e, quando nasceu a terceira, já desconfiaram desde o início. O nível de desenvolvimento da fala e da comunicação nessas crianças não acompanhou seu grau de deficiência auditiva (avaliado por instrumentos independentes), mas sim o tempo que as famílias interagiram com elas ainda pensando que elas eram capazes de ouvir. Ao descrever a evolução da filha mais velha, que conseguiu atingir um nível de desenvolvimento bem maior do que as demais, a mãe fez um comentário esclarecedor:"quando me disseram que ela era surda, eu me calei, não consegui mais ficar conversando com ela, como fazia anteriormente". A partir de então, a criança ficou privada de ricos momentos interativos, que ate então tinham Ihe possibilitado apropriar-se de vários recursos comunicativos, como gestos, posturas, ritmos e, inclusive, leitura labial.

Esses casos, dentre outros, nos mostram como os familiares e as pessoas que cuidam da criança interagem com ela e organizam seu ambiente conforme suas expectativas sobre o desenvolvimento dela e sobre seu próprio papel em relação a ela. Tais expectativas são adquiridas através de suas experiências de vida naquela cultura, aspectos que vão ter consequências sobre o desenvolvimento da criança.

Várias expectativas, crenças e teorias psicológicas têm, assim, um forte poder auto-realizador, ajudando a construir competências e deficiências. Não se fala com quem se julga surdo, não se ensina a quem não se julga capaz de aprender, recolhe-se em casa, isolada, a criança com paralisia cerebral que é julgada como incapaz de ir à escola. Concretizam-se, assim, prognósticos feitos anteriormente. Sem dúvida, as crianças e as equipes de educadores das instituições de educação infantil muito têm a ganhar conforme repensam essa situação. 


\section{Ampliando-se o foco do indivíduo para a díade}

Como viemos discutindo, o desenvolvimento não resulta apenas de características individuais, que emergem por maturação e são passíveis de serem detectadas em avaliações. Trata-se de um processo de construção social que se dá nas e através das ações e interações estabelecidas por esse indivíduo com outras pessoas, em ambientes social e culturalmente organizados.

Estudos envolvendo díades começaram a aparecer com maior frequência a partir das décadas de 1950/1960. Nessa abordagem, uma díade foi particular e amplamente privilegiada: a díade mãe-criança, que tem um status único tanto no imaginário popular como na Psicologia do Desenvolvimento, advindo, em parte, das características próprias da espécie humana.

Dentre os animais, o ser humano é aquele que, ao nascer, apresenta a maior imperícia, imaturidade e incompletude, sendo incapaz de sobreviver sozinho. Evolucionariamente, essa incompletude o teria constituído como uma espécie biologicamente social (Wallon, 1959a). Isso impõe ao bebê a necessidade íntima do outro social, de sua assistência constante, sendo-lhe assim vital uma relação próxima e constante com um parceiro da mesma espécie. Por favorecer essa relação que garante sua sobrevivência, sua evolução filogenética possivelmente otimizou seu potencial para estabelecer e manter um contato precoce com o outro, através de uma grande expressividade emocional, tanto facial como postural e gestual. $O$ bebê nasce, assim, dotado de um repertório biológico complexo, com um alto grau de organização perceptiva e expressiva que favorece seu intercâmbio com o outro social. Nesse intercâmbio, a emoção revela-se como constitutiva do vínculo com o outro (Bussab \& Ribeiro, 1998; Carvalho, 1998; Fogel, 1993).

Essa competência do recém-nascido, no entanto, só tem relevância por que os outros são capazes de ser mobilizados e de (re)agir à emoção criada no interior das relações estabelecidas. Entende-se, assim, que a díade bebê-outro evoluiu filogeneticamente como um sistema interativo (Carvalho, 1983). No âmago da construção das relações bebê-outro, esse outro social passa a atribuir à criança certas posições sociais em contextos concretos, agindo como seu mediador. É esse outro que complementa e interpreta o bebê para o mundo e o mundo para ele. É por meio do outro e dos movimentos desse outro que suas primeiras atitudes tomam forma (Wallon, 1959b).

Particularmente, a Teoria do Apego de Bowlby (1969) e a avaliação do apego através do teste da Situação Estranha (Ainsworth et al., 1978), de inspiração psicanalítica, afirmam que, pelo menos nos primeiros anos de vida, esse outro social teria de ser preferencialmente a mãe. Assim, atribuem especial relevo ao papel fundamental dessa relação para o desenvolvimento psicológico saudável da criança no decorrer da vida, enfatizando os riscos 
do não estabelecimento ou rompimento desse vínculo. Mas será que esse outro, pelo menos nos primeiros anos de vida, tem de ser a mãe?

Relatos históricos mostram que a família nuclear e, particularmente, o cuidado exclusivo da criança pequena pela mãe constitui um fenômeno recente e não generalizado no mundo (Ariés, 1981; Poster, 1979). Como aponta Lamb (2005), vários estudos têm extensamente documentado que seres humanos se desenvolvem em grupos mais complexos e diversificados que a díade mãe-criança. Na própria sociedade contemporânea, diversas formas de estruturação e reestruturação familiar têm se multiplicado, com crianças frequentemente convivendo com pais separados, com seus novos companheiros e com irmãos de outras uniões. Ademais, a crescente participação da mulher no mercado de trabalho tem aumentado significativamente o número de mães com crianças pequenas que trabalham por longos períodos diários fora de casa, fazendo com que haja um cuidado compartilhado das crianças, mesmo das bem pequenas, em instituições como a creche.

Embora tenha estimulado muita pesquisa e construído conhecimento sobre desenvolvimento afetivo nos primeiros anos de vida, e mesmo em períodos posteriores, a Teoria de Apego introduziu uma série de ideias que prevalecem no imaginário dos educadores. Ademais, introduziu sérias restrições à análise dos relacionamentos com múltiplos outros significativos, como o pai, avós, irmãos, tios, outras crianças, educadoras, os quais exercem um papel crucial no cuidado, proteção, socialização, ensino de bebês e crianças pequenas, como apontam Lamb (2005) e Lewis e Takahashi (2005), ao introduzir o número especial Beyond the Dyad em recente edição da revista Human Development.

Em função dos pressupostos clássicos, no entanto, para os teóricos do apego, o cuidado/educação da criança pequena em outros contextos, como creches, por exemplo, constituiria um risco para o desenvolvimento sadio da criança, por envolver separações diárias da mãe e um cuidado múltiplo por vários adultos (Main, 1998). Isso porque, nessa perspectiva, o desenvolvimento da criança deve se dar basicamente através da interação criança-adulto e, em especial, da criança com a mãe, com quem estabelece forte vínculo afetivo. Para averiguar a pertinência ou não dessa posição teórica, nas décadas de oitenta, noventa e mesmo nesse novo milênio, foram realizados estudos correlacionais para avaliar as consequências adversas da frequência da criança à creche, em particular estudos anglo-saxões. Apesar de resultados frequentemente contraditórios desses estudos e da crescente participação de mães com filhos pequenos no mundo do trabaIho, como discute Rosemberg (1982), no imaginário popular prevalece a pergunta: Mãe que é mãe deixa seu bebê na creche? Tal questão usualmente causa angústia, conflito e discórdia em várias mulheres e famílias, sentimentos frequentemente reforçados pela opinião do pediatra, do psicólogo e das avós. 
A influência da literatura de apego sobre a Educação Infantil, no entanto, permaneceu forte, prevalecendo a ideia de que, para evitar um eventual prejuízo para o desenvolvimento da criança, era necessário garantir-lhe na creche um cuidado materno substitutivo adequado, ideia que orientou o trabalho de pesquisa e intervenção de nosso grupo em creches filantrópicas conveniadas da região de Ribeirão Preto (Rossetti-Ferreira, 1988).

Em um dos estudos realizados (Silveira, Rossetti-Ferreira, Picolo, Delphino, \& Faria, 1987), o interesse residia em analisar se havia nas creches um cuidado materno substituto adequado, com o foco dos registros observacionais posto na díade criança-adulto. Entretanto, períodos de vários minutos se passavam sem que fosse registrada uma única interação envolvendo a criança observada e algum educador. Decidiu-se então mudar o tipo de registro, passando a focalizar o adulto responsável no momento, registrando qualquer tipo de contato que ocorresse entre ele e uma criança ou grupo de crianças. Esse registro confirmou haver, nessas creches, um ambiente interacional extremamente pobre. Por ter um grande número de crianças a seu encargo, as educadoras proviam apenas os cuidados físicos básicos, impunham ordem e disciplina, e não tinham disponibilidade para uma interação mais individualizada e afetiva com as crianças. Impressionava-nos o ritmo de trabalho automatizado das educadoras na realização das rotinas, contrastando com o longo tempo de espera das crianças, frequentemente paradas, passivas, sem nada para fazer. Por outro lado, os espaços vazios, pouco estruturados, das creches não favoreciam o desenvolvimento de atividades e brincadeiras entre as crianças. Durante o trabalho de intervenção e em treinamentos com as educadoras, procurávamos, embora com poucos resultados, estimulá-las a aproveitar cada oportunidade para interagir com as crianças, sobretudo durante a realização de atividades de rotina com uma criança, como na hora de dar banho ou trocar, por exemplo, proposta que se mostrou inviável na situação concreta que elas enfrentavam. Naquelas condições, a orientação dada às estagiárias e educadoras apenas aumentava o tempo de espera das outras crianças, que aguardavam sua vez de serem atendidas.

O modelo de cuidado provido por uma mãe em uma família nuclear, assim, mostrava-se claramente inadequado nas situações das creches estudadas e, provavelmente, em qualquer situação de educação coletiva de crianças. Basta imaginar o desalento de uma mãe cuidando de seus quatro ou cinco gêmeos no primeiro ou segundo ano de vida, número esse considerado razoável para compor um grupinho de crianças do berçário sob a responsabilidade de uma educadora.

Isso nos levou a repensar o modelo de cuidado materno substitutivo que estávamos propondo para as creches e o próprio paradigma de desenvolvimento da criança que havia fundamentado nosso projeto de pesquisa e intervenção, e que propunha que o desenvolvimento da criança pequena se dá, basicamente, na e pela interação com a mãe, com quem ela estabelece uma relação individualizada privilegiada. 
É interessante notar que estudos escandinavos, franceses e italianos da época (CRESAS, 1991; Fiorani \& Musatti, 1986; Mantovani \& Terzi, 1987; Pramling \& Lindalh, 1992) dedicavam-se mais ao estudo das interações de crianças pequenas em creche e investigavam novas formas para promover ambientes de educação coletiva de qualidade que fossem acolhedores para elas e suas famílias, e adequados às suas necessidades desenvolvimentais.

A creche constitui um contexto de socialização diverso do familiar, pois nele um adulto, que não tem necessariamente um vínculo afetivo especial com cada criança, cuida simultaneamente de várias crianças pequenas. Nesse contexto, a ênfase em uma estimulação individualizada sobrecarrega a educadora e aumenta o tempo de espera das crianças. Embora a educadora tenha um forte poder acolhedor e estruturador, nesse ambiente coletivo há também outros parceiros de interação disponíveis, as outras crianças que atraem fortemente o interesse da criança pequena.

\section{O foco na interação de crianças}

Ao longo das últimas quatro décadas, a área de estudo do desenvolvimento humano passou por intensas mudanças conceituais e metodológicas relacionadas aos processos interativos de crianças, particularmente de bebês, como discutem Anjos, Amorim, Franchi e Vasconcelos e Rossetti-Ferreira ( 2004). A década de 1960, por exemplo, foi marcada pelos estudos sobre a relação adulto-criança e, particularmente, sobre a relação mãe-criança. Na década de 1970, estudos sobre interação questionavam a possibilidade de haver contribuições, a partir do contato com pares, para o desenvolvimento das competências das crianças, fossem essas competências cognitivas ou interpessoais. Para alguns autores, não era claro que o "contato social" ou "comportamento socialmente dirigido" pudesse significar interação propriamente dita; e nem mesmo era clara a função da relação que um bebê estabelecia com outro bebê. Alguns poucos autores, no entanto, reconheciam a existência de processos interativos de bebês, buscando estudá-los. Aparecem assim estudos sobre interação de crianças pequenas, em geral feitos em laboratório com espelhos unidirecionais, onde se registrava o comportamento socialmente dirigido a outra criança, particularmente o jogo paralelo e, por vezes, a imitação (Mueller \& Lucas, 1975), sendo que as crianças observadas eram habitualmente estranhas umas às outras.

Na década de 1980, ainda se dizia discutível a capacidade de interação do bebê com o coetâneo, em função de que os comportamentos socialmente orientados eram frequentemente isolados e sem articulações que permitissem interações mais longas e sustentáveis. De modo geral, entendia-se que, por não serem capazes de perceber os desejos ou intenções 
da outra, de se ajustar ao que a outra quer, ou de negociar um acordo conjunto, era difícil para essas crianças estabelecerem interações mais complexas e duradouras. Essas capacidades, que para os autores dependeriam e acompanhariam o desenvolvimento simbólico, possibilitariam à criança atribuir significados diferentes a um mesmo objeto no jogo de faz de conta, assumir diferentes papéis, jogar e trocar de papéis e posições com os companheiros. Obviamente, o domínio da linguagem facilita muito esses acordos, favorecendo a comunicação entre crianças.

Alguns estudos realizados nessa época, no entanto, já mostraram que a atividade e a interação de crianças não dependiam apenas do seu nível de competência cognitiva ou linguística, e apontaram ricas interações criadas por crianças de menos de três anos, em geral no contexto de creches de boa qualidade, e com companheiros já conhecidos (Camaioni, 1980; Carvalho \& Carvalho, 1990; Carvalho \& Pedrosa, 2002; Oliveira, 1988; Rayna, 1987; Stambak \& Verba, 1986).

O marco, na década de 1980, que vai modificar radicalmente a abordagem dessa faixa etária e ainda a questão das interações de bebês, foi o início do uso de novos recursos de observação de crianças, especialmente a vídeogravação. Essa resultou em novos avanços na área, já que o recurso possibilita a preservação do fenômeno, propiciando repetição da situação observada e mais tempo para reflexão sobre a mesma, possibilitando o enriquecimento de sua análise (Carvalho et al., 1996).

Nesse sentido, como a revisão de Anjos et al. (2004) apontou, começou a surgir um maior número de autores que reconheciam, já no primeiro ano de vida, as capacidades de trocas recíprocas, as quais antecederiam a locomoção, a fala e as habilidades cognitivas maduras, os bebês podendo interagir entre si, mesmo que com habilidades e recursos limitados. Ainda, capacidades comunicativas passaram também a ser estudadas com foco no afeto, nos gestos, na imitação e comunicação não-verbal.

O estudo de interações de crianças de 1, 2 e 3 anos feito a partir de análises microgenéticas de episódios observados em creches, em situação de brincadeira não diretamente dirigida pelo educador (Oliveira, 1988) e de almoço (Paula \& Oliveira, 1995), ambas videogravadas em creches públicas, possibilitou captar nuances nas situações que as crianças, desde cedo, criam para significar o mundo e a si mesmas. Tal linha de investigação tem se mostrado uma forma privilegiada de ouvir as crianças, apreendendo seus gestos, posturas corporais, verbalizações, enfim, sua fala, em diferentes posições discursivas, ocupando papéis diversos.

Já na década de 1990 e início do novo milênio, muitos pesquisadores buscaram aperfeiçoar seus métodos de investigação dos elementos reguladores do comportamento e dos sistemas de interação, além das estratégias de aproximação social e das habilidades comunicativas. Além disso, o conceito de interação passou por reelaborações, passando a ser concebido como englobando mais do que o fazer algo juntos, contemplando 
a regulação recíproca, implícita e não necessariamente intencional. Nesse período, ainda, houve o sentido de teorização dos processos interativos, como os de intersubjetividade, como parte de outros processos do desenvolvimento do primeiro ano de vida (Bräten, 1998; Fogel, 1993).

Dentro do nosso grupo, nessa linha de estudos, Franchi e Vasconcelos, Amorim, Anjos e Rossetti-Ferreira (2003) apontaram que, no sistema de interações sociais da criança, em seu primeiro ano de vida, existe um desajeitamento ou uma "incompletude motora" que, ao invés de necessariamente representar obstáculos às interações dos bebês com seus pares, podem representar um elemento que favoreça a sua ocorrência, algo que pode conduzir ao encontro com o outro e à novidade. Ao se atentar para o desajeitamento motor dos bebês, é possível perceber também pistas importantes de como o desenvolvimento das interações está ocorrendo nessa idade.

Ainda, no estudo de Anjos et al. (2004), identificamos inúmeros processos interativos envolvendo bebês, mesmo os bem novinhos. Essas interações ocorriam muitas vezes decorrentes do acaso, de encontros fortuitos. Porém, era possível verificar que várias ações e emoções das crianças indicavam uma busca pelo outro. Evidentemente, muitos desses eventos acabavam por se perder, enquanto outros se desdobravam e se concretizavam. A análise desse trabalho possibilitou compreender que não é o fazer algo conjuntamente com o outro - que é o comportamento mais facilmente observável - que possibilita apreender as interações de bebês, dado que as ações iniciadas por um dos bebês em direção ao outro não necessariamente resultavam em atividade conjunta. Além disso, suas ações delineavam-se de forma fluida, entrecortada, interrompida por diferentes situações em alguns episódios, sendo posteriormente retomadas. Dessa forma, revelavam não ser episódios breves propriamente ditos, abarcando muito mais do que esse fazer algo juntos. O comportamento mostra-se regulado, mesmo à distância, ou mesmo que um dos parceiros não saiba que ele está regulando o comportamento do outro. Os processos passaram, assim, a ser entendidos dentro de uma noção de "campo interativo", onde há interesses pelo outro, orientação de comportamentos dirigidos ao outro e derivados pelo outro, além de regulação de suas ações pela própria ação e a do outro (Anjos, 2002).

Os trabalhos de Ercília de Paula (1994) e Adriana Anjos (2005) mostraram ainda que, apesar da idade das crianças (em que ainda não fazem uso de pensamento e fala verbais), tais eventos resultavam na coconstrução de significados presentes nas ações e reações das crianças naquele contexto específico. Como numa dança, com encontros e desencontros, os múltiplos significados e pontos de vista construídos na dinâmica dos acontecimentos começavam a emergir nas situações, apesar de ou graças à participação dos adultos, mas principalmente por parte das crianças que se colocavam como coparticipantes na relação com o outro. 
Essas atribuições de significados eram feitas pelas crianças não de forma intencional, sendo construídas e comunicadas através dos gestos, do olhar, da postura corporal, do choro, dos sorrisos, das vocalizações e das emoções, na relação com o outro. Nesses momentos interativos, um e outro se envolviam e contagiavam o parceiro. Em tais processos, por exemplo, ora a criança era posicionada/posicionava-se no papel de ameaçadora, ora no papel de submissa, ora de protegida e amparada, como foi percebido no estudo de Anjos (2005), ora a criança assumia o papel da educadora e agia em relação aos colegas estimulando-os a comer, ou mesmo oferecendoIhes comida com sua colher, tal como mostrou de Paula (1994).

Assim, múltiplos posicionamentos foram observados, nos casos de uma mesma criança negociando os diferentes significados e posicionamentos com vários interlocutores em momentos e situações diversas, ou seja, dentro de uma mesma relação ou dentro de um episódio interativo. Além disso, em função da proximidade e da história experimentada na relação entre as crianças, ao estabelecerem na creche uma relação mais contínua e prolongada, observava-se uma abreviação dos comportamentos na interação.

Os processos de abreviação têm sido analisados fundamentalmente nos casos das interações mãe-bebê (Lyra, 2000) e se referem a um processo relativo à atenção e comunicação entre os parceiros, decorrente de sucessivas atividades anteriores de recorte efetuadas pela díade. De modo abreviado, aparecem elementos anteriormente negociados de forma prolongada. Nosso projeto procurou ampliar o uso dessa noção para avaliar sua ocorrência na relação do bebê e seu coetâneo, em situações específicas (Costa, 2008).

Além disso, verificou-se a abreviação de significações, como proposto por Carvalho, Império-Hamburger e Pedrosa (1997). Esse processo foi observado em um dos episódios analisados por Anjos (2005), que analisou a brincadeira de faz-de-conta entre as crianças em uma creche, em que uma criança de 13 meses de idade foi observada dramatizando ludicamente um caso de perseguição pelo coetâneo.

Identificou-se ainda episódios de empatia. À análise, em dois estudos, pesquisadores identificaram que crianças de 13 meses de idade fazem gestos de consolo e buscam ajuda por parte dos adultos, frente a um choro forte e insistente de uma criança de nove meses de idade. Tais comportamentos sugerem a presença de empatia de um bebê em relação a outro, questão pouco reconhecida nessa faixa etária (Anjos, 2005; Bussab, Pedrosa, \& Carvalho, 2007; Carvalho \& Pedrosa, 1993).

De um modo geral, em cada um dos episódios selecionados, analisamos interações de bebês que se encontravam em diferentes momentos do desenvolvimento cognitivo/motor. Devido à diferença de idades entre as crianças (4-13 meses), era comum que, dividindo o mesmo espaço, encontrássemos crianças que ainda não engatinhavam interagindo com ou- 
tras que até já andavam, havendo um interesse e um conjunto de relações e regulações que se davam mutuamente entre as crianças, modificando mesmo seu comportamento e alterando suas habilidades. Isso nos levou a romper com a tradicional noção de que apenas o mais desenvolvido é capaz de contribuir para o desenvolvimento do outro menos desenvolvido. Ao contrário, a análise nos levou a assumir que ambos encontram-se constituindo habilidades, papéis e significados nos processos interativos.

Essa centralidade do Eu em relação ao Outro em tão tenra idade, para nós, é algo essencial para entendermos o processo interativo de crianças no primeiro ano de vida, que mesmo não dispondo de um projeto de interação, são capazes de agir e reagir em direção ao outro, de se colocar disponíveis para um diálogo que não tem a intenção de ser pronto e acabado, mas que é continuamente explorado, vivido e (re)criado.

Por outro lado, Legendre (1989), Campos de Carvalho e Rubiano (1996) e Campos de Carvalho e Rossetti-Ferreira (1993) mostraram como o arranjo espacial e a presença de objetos no ambiente apoiam a organização de grupinhos de crianças e a interação continuada entre eles. Na prática, verificou-se que não basta apenas arranjar o espaço e montar cantinhos para a realização de atividades diversificadas, mas é necessário que essa organização se associe a práticas pedagógicas que propiciem condições de desenvolvimento adequadas para aquele grupinho de crianças, observando e estimulando suas competências, e respeitando seus interesses.

Pensar o desenvolvimento humano, principalmente no que se refere às relações da pessoa com o seu meio sócio-histórico-cultural, para nós, ganha novas cores a partir de uma perspectiva dialógica, situada em práticas sociais cotidianas (Oliveira, 2002; Spink, 1999). Tal perspectiva procura entender e apreender como as características das pessoas em interação, seu modo de ser e de agir, em suas relações e interações, continuamente negociadas e (re)criadas através de um processo dinâmico e dialético de comunicação. Nesse processo, as pessoas se constituem reciprocamente, dando sentidos a si próprios, aos outros e a seu entorno.

A matriz sócio-histórica (Amorim, 2002; Amorim \& Rossetti-Ferreira, 2004) que permeia todo o processo tem concretude no aqui-e-agora de cada situação e circunscreve os limites e possibilidades de percursos que as interações e as pessoas poderão tomar. Esses vários elementos entrelaçados nos fazem considerar, então, o desenvolvimento a partir de uma abordagem dialógica em que pessoa e meio são partes indissociáveis de um mesmo processo, o que nos leva a pensar tais processos a partir de novos paradigmas. 


\section{Deslocando o foco do indivíduo e da díade, para apreender}

\section{a complexidade}

Como as discussões anteriores revelam, torna-se necessário romper com o foco no indivíduo (ainda mais quando centrado exclusivamente na criança) e na díade mãe-criança, procurando investigar para além dessa díade. Mais do que isso, torna-se fundamental e emergente reconhecer e buscar compreender as situações desenvolvimentais dentro de um paradigma da complexidade (Morin, 1990), abrindo-se à diversidade, às múltiplas perspectivas possíveis. Essa busca constitui uma tendência atual, não apenas das ciências humanas e sociais, mas também das exatas e biológicas (Bertalanffy, 1975; Kuhn, 1962). Na Psicologia, a preocupação mais evidente refere-se a apreender e analisar fenômenos complexos em suas múltiplas dimensões de maneira integrada e inclusiva, em uma visão geralmente referida como sistêmica.

Os usos e interpretações da abordagem sistêmica, entretanto, variam muito. No entanto, alguns pontos razoavelmente consensuais podem ser apontados: o foco inicial no indivíduo amplia-se para as pessoas em interação, a tendência de olhar a influência de uma pessoa sobre a outra de uma perspectiva apenas unidirecional é superada pelo reconhecimento da interdependência entre as diferentes pessoas e da reciprocidade e do sinergismo entre elas, e a preferência pelo estudo do sujeito em situações de laboratório, tendo em vista assegurar um maior controle de variáveis, é substituída por uma visão ecológica, a qual requer uma investigação do desenvolvimento em um contexto concreto. Nessa visão, a interdependência e a mútua e contínua constituição e transformação da pessoa e do seu ambiente devem ser levadas em conta.

O autor que melhor representa essa visão ecológica e sistêmica na Psicologia do Desenvolvimento é Bronfenbrenner. Sua proposta se desenvolveu, mais inicialmente na década de 1970, a partir de uma ampla revisão bibliográfica que abarcou quase um século de pesquisa realizadas no campo da Psicologia do Desenvolvimento. Com isso, ele trabalhou com grandes amostras e complexas análises transversais e multifatoriais dos eventos e situações.

Essa abordagem do problema por Bronfenbrenner difere das pesquisas conduzidas por nosso grupo, que partem em geral de estudos de caso, com pequenas amostras e uma diversificada base de dados, buscando analisar as interações situadas no aqui e agora, articuladas a outros tempos históricos. Tais investigações, quando possível, têm sido complementadas por estudos mais amplos, como os sociodemográficos, para construir uma visão mais geral da situação - como exemplo, citamos estudos de caso de inclusão escolar de Roriz (2005) e Yazlle (2000), articulados com análise de censo da inclusão na rede de educação municipal, de Martins (2008). 
Partindo de um contínuo diálogo entre teoria, investigação e práxis, procuramos compreender os processos de transformação, ao longo do tempo e das situações, das pessoas em interação e dos contextos, alternando o olhar do micro ao macro, do macro ao micro. Concebemos tais processos como se dando nas e por meio das múltiplas interações estabelecidas pelas pessoas em uma rede de relações significativas tecida em contextos social e culturalmente organizados, onde pessoas e contextos se constituem reciprocamente, imersos em uma malha de elementos de natureza semiótica. Concebendo tais questões, elaboramos uma perspectiva teórico-metodológica - a perspectiva da Rede de Significações (RedSig).

Rede de Significações: uma perspectiva teórico-metodológica para enfrentar o desafio da complexidade em estudos sobre o desenvolvimento humano

A perspectiva da RedSig (Rossetti-Ferreira,Amorim, \& Silva, 2000,2004; Rossetti-Ferreira, Amorim \& Vitória, 1994, 1996, 1997), elaborada para a investigação e compreensão dos complexos processos de desenvolvimento humano, situa-se no contexto das pesquisas que focalizam os processos de construção dos significados e sentidos, ou seja, do ato, da ação de significar (significa-ação) como temas centrais da Psicologia (Bruner, 1997; Silva, 2003).

Nos vários estudos realizados pelo CINDEDI, os desafios e a busca por unidades de análise capazes de abarcar essa complexidade foram nos apontando o caráter central das relações e interações, principalmente em sua qualidade processual. Entendemos que nas interações sociais, pela dinâmica segmentação e integração de fragmentos de experiências passadas em situações presentes, através dos processos de imitação de modelos (fusão) e do confronto (diferenciação) das necessidades, sentidos e representações, cada pessoa negocia os significados que atribui a si, ao outro e à situação como um todo (Oliveira, 1988; Rossetti-Ferreira, Amorim \& Vitória, 1996).

No processo interativo, o conjunto das ações possíveis de serem realizadas e o fluxo de comportamentos são delimitados, estruturados, recortados e interpretados pela ação do outro, e também, por um conjunto de elementos orgânicos, físicos, interacionais, sociais, econômicos e ideológicos. Todos eles interagem dinâmica e dialeticamente, compondo uma rede, a qual contempla condições macro e microindividuais e estrutura um universo semiótico, constituindo o que vimos denominando Rede de Significações (Rossetti-Ferreira, Amorim, \& Silva, 2000, p. 282).

Dessa perspectiva, no trabalho de investigação faz-se necessário ir além do levantamento e identificação dos diferentes elementos presentes no desenvolvimento. Deve-se, assim, buscar apreender as diferentes interconexões e associações entre eles, suas relações de proximidade e subordi- 
nações, seus entrelaçamentos, para representar e exprimir a complexidade da forma e do movimento do processo de desenvolvimento humano.

Desde que nasce, e mesmo antes, na gestação, a criança está imersa nas práticas sociais de algum grupo de pessoas que atuam como seu ambiente de aprendizagem e desenvolvimento. Suas formas de agir, pensar, sentir, embora influenciadas por fatores biológicos, não resultam apenas deles. Elas são construídas conforme as possibilidades de participação da criança em seu meio sociocultural em atividades onde interage com diferentes parceiros. Nascida em uma cultura historicamente constituída, a experiência da criança nessa e em outras culturas vai lhe exigir e possibilitar a apropriação de múltiplos signos criados pelos seres humanos para dar sentido às suas relações com o mundo da natureza e o da cultura, e a sua relação com si mesma. Isso coloca a questão da aprendizagem no centro das preocupações dos educadores.

\section{O olhar para a atuação dos educadores}

O aprendizado pode ser provocado por colaboração com diferentes parceiros na realização de determinadas tarefas, por observação e imitação, ou por transmissão social. Aprende-se, em especial, na relação com o outro, não só o professor, mas também outras crianças. Além disso, aprende-se consigo mesmo, ou a partir de objetos e de outras produções culturais abstratas.

A mediação do professor na aprendizagem se faz à medida que suas ações buscam familiarizar a criança com significações historicamente elaboradas para orientar o agir das pessoas e compreender as situações e os elementos do mundo. Ele age de uma forma indireta, pelo arranjo do contexto de aprendizagem das crianças: os espaços, os objetos, os horários, os agrupamentos infantis (Mello, 1999). Em estudo sobre as práticas discursivas dos educadores de creches (Oliveira, 1995), apontamos que o educador atua de modo direto conforme interage com as crianças e lhes apresenta modelos, responde ao que elas perguntam, faz perguntas para conhecer suas respostas, as pega no colo quando se emocionam e, por vezes, opõese ao que elas fazem ou dizem para ajudá-las a ampliar seu olhar, ensinar as regras sociais de seu grupo social ou aperfeiçoar seu modo de sentir as situações. Nesse sentido, as ações do professor apontam significados que têm que interagir com as ações (e os significados) das crianças. Daí a importância do professor centrar nelas o seu olhar.

Tais ações do professor junto à criança são cultural e historicamente constituídas e baseiam-se em especial na representação que ele faz do seu papel e na concepção de criança e de educação infantil que ele tem. Por exemplo, se ele não acredita que os bebês são capazes de interagir com companheiros, ele os coloca em locais separados e os atende individual- 
mente. Por sua vez, se o professor se fundamenta na ideia que eles podem, desde pequenos, interagir, trocar objetos com os companheiros, imitar os gestos, expressões e vocalizações de outro bebê, ele busca organizar áreas acolhedoras e estimulantes em diferentes espaços da creche que eles podem explorar em duplas, trios etc.

Conhecer as preferências das crianças, a forma delas participarem nas atividades, seus parceiros prediletos para a realização de diferentes tipos de tarefas, suas narrativas, pode ajudar o professor a reorganizar as atividades de modo mais adequado à realização dos propósitos infantis e das aprendizagens coletivamente trabalhadas.

A observação sistemática do comportamento de cada criança em diversificados momentos é condição necessária para se investigar como ela se apropria de modos de agir, sentir e pensar culturalmente constituídos. Conforme as observações vão sendo feitas e registradas, é possível avaliar o trabalho realizado e refletir sobre o andamento do mesmo, problematizando certos aspectos. Tal registro é fundamental no exame de melhores caminhos para orientar as aprendizagens das crianças.

Da perspectiva da RedSig, a avaliação do processo de aprendizagem e desenvolvimento na creche não pode ter como objeto apenas as ações infantis, mas deve incidir sobre todo o contexto de aprendizagem: as atividades propostas e o modo como foram realizadas, as instruções e os apoios afetivos dados, a forma como o professor respondeu às manifestações e às interações das crianças, os agrupamentos que as crianças formaram na execução de uma atividade, o material oferecido, o espaço e tempo garantidos para a realização das atividades, e outros. A partir disso, espera-se que o professor possa pesquisar quais elementos podem estar contribuindo, ou dificultando, a aprendizagem e o desenvolvimento das crianças e então fortalecer, ou modificar, a situação. Dentro da perspectiva, no entanto, devemos ir além desse foco no professor, abarcando também considerar as condições da instituição em si - quais recursos oferece, como se dão as relações entre a equipe de professores e com os demais funcionários/educadores que atuam no contexto da escola, qual é a relação com a comunidade e as famílias das crianças, dentre outros.

Como uma forma de abordar essa complexidade, a partir dessa perspectiva da RedSig, vamos trazer aqui a discussão da brincadeira de crianças em creches e os processos de desenvolvimento por elas promovidos.

Em estudos que realizamos, verificamos que as interações que as crianças pequenas estabelecem nas brincadeiras que criam nas interações com outras crianças são mediadas por um conjunto de elementos, tais como: a forma de organização dos espaços de modo a propiciar maior ou menor oportunidade de interação para pequenos grupos e de construção de parcerias privilegiadas, a forma de organização do tempo que envolve a regularidade de experiências de brincadeiras tradicionais ou de faz-deconta na creche, os materiais disponíveis, a mediação do professor (que de- 
pende da representação que ele faz da situação), a possibilidade das crianças imitarem os parceiros e representarem corporal e linguisticamente situações anteriormente vivenciadas ou fantasiadas, as experiências vividas na creche, na família, ou observadas na TV, em DVDs, livros, ou propiciadas por excursões e passeios em praças, fábricas, bibliotecas, museus etc. Tais experiências apresentam elementos para o faz-de-conta e a narrativa de contos de fada e são modificados pelo brincar das crianças que revoluciona sua própria forma de brincar.

Com esse olhar mais abrangente é possível levantar pontos que precisam ser revistos de modo a concretizar o papel do ambiente como recurso para o desenvolvimento das crianças. Em outras palavras, a análise das dimensões deve auxiliar na gestão dos ambientes de aprendizagem pelo professor e demais educadores de modo a efetivar o Projeto Pedagógico de cada unidade.

\section{Considerações finais}

Como discorremos ao longo do texto, nossa experiência tem revelado que múltiplos podem ser os percursos de desenvolvimento. No entanto, no campo da Psicologia do Desenvolvimento, essa multiplicidade tem sido contraposta com uma forma fragmentada e descontextualizada de considerar os processos, apontando para poucos caminhos, bastante delimitados e restritivos. No caso de desvios nos caminhos considerados ideais ou de modificações na forma de ocorrerem (como o contexto onde se dão - creche; ou na forma das relações serem estabelecidas com a mãe, por exemplo), há uma predição de um percurso visto como "desviado", onde a saúde mental, emocional, cognitiva e social da criança pode ser prejudicada. Tais concepções estruturam-se na forma de relacionar-se e atuar junto a essas crianças e suas famílias, contribuindo fortemente para constituir o percurso anunciado.

Todo discurso científico sempre fala de algum lugar, para alguém, dentro de uma determinada época e contexto, a partir de certas perguntas, tendo como base determinadas abordagens teórico-metodológicas. Esses discursos orientam certas formas de recorte do fluxo dos fenômenos (e não outras), certas ações e intervenções (e não outras), e consequentemente certos percursos desenvolvimentais (e não outros). Assim, cabe ao pesquisador a tarefa de traçar essas múltiplas vozes, identificando respostas às perguntas acima colocadas, para posicionar-se criticamente com relação a elas.

Tem-se que ir além da criança, além do indivíduo que se desenvolve e apreendê-lo dentro das redes de significações em que se encontra inserido. Deve-se buscar identificar as várias relações estabelecidas nos diversos contextos, de modo a compreender o seu ser e estar no mundo. 
Deve-se buscar identificar os vários elementos socioeconômicos, políticos, históricos e culturais que atravessam seus processos de desenvolvimento. Somente assim estaremos considerando a complexidade do fenômeno em que se encontram as crianças e seremos capazes de interpretar e atuar condignamente com as pessoas e as instituições significativas à situação. Sem dar conta do processo mais amplo, não se poderá modificar e ajudar a construir outros percursos possíveis, que levem as crianças de fato a ricas oportunidades de desenvolvimento nas instituições de Educação Infantil.

\section{Looking at children and their others: a research history on early childhood education}

Abstract: Aiming to contribute to the current and intense process of revision of conceptions and educational practices mediating learning and development of young children in day care centers and pre-schools, and based on our research experiences at CINDEDI, this paper approaches several questions which, in our view, are relevant for the understanding of collective education. How does developmental research contribute to this discussion? What conceptions about development is it based on? Which methodological perspectives are more promising for the comprehension of the ways children and their teachers act and change with their experiences? How to understand notions such as developmental stages, teachers' role in the learning process, factors explaining infant development and developmental evaluations in infancy? Both family and childcare professionals interact with the child and organize his/her environment according to their expectations about his/ her development and their own role in this process. These expectations are built through their life experiences in their particular culture. Many expectations, beliefs and psychological theories have, thus, a strong self-fulfilling power, helping to build competencies and deficiencies. Children and the professional staff of Child Education institutions have undoubtedly much to gain from reflecting on these questions.

Keywords: Child education. Conceptions on development. Child-child interaction. Network of meanings.

\section{Un regard sur l'enfant et ses autres: une histoire de recheche sur l'éducation des enfants}

Résumé: Au but de concourir à l'intense process actuel de révision sur des conceptions et du choix et affermissement des pratiques pédagogiques intervenantes dans l'apprentissage et le développement des enfants dans les services 
d'accueil de la petite enfance, et avec l'appui des experiences de recherche du CINDEDI, on approche ici des questions que nous semblent importantes pour comprendre le phénomène de l'éducation collective des bébés. Quelles sont les contributions de la recherche sur le développement humaine à ce débat? Quelle est la conception de développement sur laquelle elles s'appuient? Quelle perspective méthodologique peut ouvrir des chemins productives à la compréhension des manières par lequelles les enfants et leurs éducateurs agissent et se modifient avec leur experiences? Comment est-ce qu'on doit comprendre les notions de stages de développement, la fonction du professeur dans l'apprentissage,les facteurs qu'expliquent le développement de l'enfant et l'évaluation du développement à cet âge? Autant la famille que les éducateurs des services d'accueil de la petite enfance agissent vers l'enfant et organisent son ambiance selon leurs expectatives sur son développement et sur leur role dans ce process. Cettes expectatives sont acquis au cours de leur experiences au sein d'une culture donée. Plusieurs expectatives, croyances et théories psychologiques ont, donc, la puissance d'auto-réalisation et peuvent councourir à la construction de compétences aussi que de défauts. La réflexion sur cettes questions peut sans doute être d'advantage pour les enfants et pour les éducateurs des Services d'accueil de la petite enfance.

Mots-clés: Education de la petite enfance. Conceptions sur le développement. Intéraction des enfants. Réseau de significations.

\section{Una mirada al ninõ y sus otros: una historia de investigación sobre la educación infantil}

Resumen:Con el objetivo decontribuir al actualyintenso proceso de revisión de concepciones, y de selección y fortalecimiento de practicas pedagógicas mediadoras del aprendizaje y desarrollo de los niños en guarderías y preescuelas, y embasados en las experiencias de pesquisa del CINDEDI, abordamos en este texto una serie de cuestiones que nos parecen relevantes para la comprensión del fenómeno de la educación colectiva de bebés. ¿Qué contribuciones pueden ofrecer a esta discusión las pesquisas sobre el desarrollo humano? ¿En cuál concepción de desarrollo se basan ellas? ¿Qué perspectiva metodológica puede abrir caminos prometedores para se comprender como os niños y sus educadores actuan y se modifican con la experiencia? ¿Como entender las nociones de estadios de desarrollo, la función del profesor en el aprendizaje, los factores explicativos del desarrollo infantil y su evaluación? Tanto los familiares así como los profesionales de la guardería interaccionan con el niño y organizan su entorno según sus expectativas sobre su desarrollo y sobre su propio rol relativo en ese proceso. Tales expectativas son adquiridas mediante sus experiencias de vida en aquella cultura. Varias expectativas, credos y teorías psicológicas tienen, por eso, un fuerte poder auto-realizador, que ayuda a construir competencias y deficiencias. Sin 
duda, los niños y los equipos de educadores de las instituciones de Educación Infantil tienen mucho por ganar conforme repiensan esas cuestiones

Palabras clave: Educación infantil. Concepciones de desarrollo. Interacción niño-niño. Red de significaciones.

\section{Referências}

Ainsworth, M. D. S., Blehar, M. C., Waters, E., \& Wall, S. (1978). Patterns of attachment. New Jersey: Lawrence Erlbaun.

Amorim, K. S. (2002). Bebês com quadros orgânicos patológicos na creche: rede de significados, mediadores das práticas de cuidados. Tese de Doutorado, Programa de pós-graduação em Psicologia, Faculdade de Filosofia, Ciências e Letras de Ribeirão Preto, Universidade de São Paulo, Ribeirão Preto, SP.

Amorim, K. S., \& Rossetti-Ferreira, M. C. (2004). A matriz sócio-histórica. In M. C. Rossetti-Ferreira, K. S. Amorim, A. P. S. Silva \& A. M. A. Carvalho (Orgs.), Rede de significações e o estudo do desenvolvimento humano (pp. 94-112). Porto Alegre: Artmed.

Anjos, A. M. (2002). Estudo de processos interativos de bebês. Monografia de Bacharelado em Psicologia, Faculdade de Filosofia, Ciências e Letras de Ribeirão Preto, Universidade de São Paulo, Ribeirão Preto, SP.

Anjos, A. M. (2005). Processos interativos de bebês, no decorrer do primeiro ano de vida, analisados a partir de uma perspectiva dialógica. Dissertação de Mestrado, Programa de pós-graduação em Psicologia, Faculdade de Filosofia, Ciências e Letras de Ribeirão Preto, Universidade de São Paulo, Ribeirão Preto, SP.

Anjos, A. M., Amorim, K. S., Franchi e Vasconcelos, C. R., \& Rossetti-Ferreira, M. C. (2004). Estudo de processos interativos de bebês. Estudos de Psicologia, 9(3), 513522.

Ariès, P. (1981). História social da criança e da família. Rio de Janeiro: Livros Técnicos e Científicos.

Baltes, P. B., Staudinger, U. M., \& Lindenberger, U. (1999). Life-span developmental psychology. Annual Review of Psychology, 50, 471-507.

Bertalanffy, L. V. (1975). Teoria geral dos sistemas. Petrópolis, RJ: Vozes.

Bowlby, J. (1969). Attachment and Loss. Attachment. New York: Basic Books.

Bräten, S. (Ed.). (1998). Intersubjective communication and emotion in early ontogeny. Cambridge: Cambridge University Press.

Bronfenbrenner, U. (1977). Toward an experimental ecology of human development. American Psychologist, 32, 513-531.

Bronfenbrenner, U. (1979). The ecology of human development. Cambridge: Harvard University. 
Bronfenbrenner, U. (1986). Ecology of the family as a context for human development: Research perspectives. Developmental Psychology, 22(6), 723-742.

Bruner, J. (1997). Atos de significação. Porto Alegre: Artes Médicas.

Bussab, V.S. R., Pedrosa, M. I., \& Carvalho, A. M. A. (2007). Encontros com o outro: empatia e intersubjetividade no primeiro ano de vida. Psicologia USP, 18(2), 99-133.

Bussab, V. S. R., \& Ribeiro, F. J. L. (1998). Biologicamente cultural. In L. Souza, F. Q. Freitas \& M. M. P. Rodrigues (Orgs.), Psicologia: reflexões (im)pertinentes (pp. 175193). São Paulo: Casa do Psicólogo.

Cairns, R. B. (1983). The emergence of developmental psychology. In W. Kessen (Org.), Carmichael's handbook of child development: Vol. 1 History, theory, and methods (pp. 41-102). New York: John Wiley and Sons.

Camaioni, L. (1980). L'interazione tra bambini. Roma: Armando Armando.

Campos de Carvalho, M. I., \& Rubiano, M. R. B. (1996). Organização do espaço em instituições pré-escolares. In Z. M. R. Oliveira (Org.), Educação infantil: muitos olhares (3a ed., pp. 107-130). São Paulo: Cortez.

Campos de Carvalho, M. I., \& Rossetti-Ferreira, M. C. (1993). Importance of spatial arrangements for young children in day care centers. Children's Environments, 10(1), 19-30.

Carvalho, A. M. A. (1983). O desenvolvimento da criança. Pediatria Moderna, 18(5), 269-280.

Carvalho, A. M. A. (1998). Etologia e o comportamento social. In L. Souza, F. Q. Freitas \& M. M. P. Rodrigues (Orgs.), Psicologia: Reflexões (im)pertinentes (pp. 195-224). São Paulo: Casa do Psicólogo.

Carvalho, A. M. A., Bergamasco, N. H. P., Lyra, M. C. D. P., Pedrosa, M. I. P. C., Rubiano, M. R. B., Rossetti-Ferreira, M. C., et al. (1996). Registro em vídeo na pesquisa em psicologia: reflexões a partir de relatos de experiência. Psicologia: Teoria e Pesquisa, 12(3), 261-267.

Carvalho, A. M. A., \& Carvalho, J. E. C. (1990). Estratégias de aproximação social em crianças de dois a seis anos. Psicologia USP, 1(2),117-126.

Carvalho, A. M. A., Império-Hamburger, A., \& Pedrosa, M. I. (1997). Interaction, regulation and correlation: a conceptual discussion and empirical examples in the context of human development. In M. Lyra \& J. Valsiner (Orgs.), The construction of psychological processes in the course of interpersonal communication (pp. 135-151). Norswod: Ablex.

Carvalho, A. M. A., \& Pedrosa, M. I. (1993). Conforting behavior in young children: Implications to the ontogeny of empathy. Abstracts, 12th Biennal Meetings of ISSBD (p. 54). Recife, PE.

Carvalho, A. M. A., \& Pedrosa, M. I. (2002). Cultura no grupo de brinquedo. Estudos de Psicologia, 7(1), 181-188.

Costa, C. A. (2008). Processo de abreviação em processos de interação bebê-bebê. Monografia de Bacharelado em Psicologia, Faculdade de Filosofia, Ciências e Letras de Ribeirão Preto, Universidade de São Paulo, Ribeirão Preto, SP. 
CRESAS. (1991). Accueillir à la crèche, à l'école: il ne suffit pas d'ouvrir la porte! Paris: INRP-L'Harmattan.

Fiorani, A., \& Musatti, T. (1986). L'inserimiento del bambino al nido e il processo di socializzazione tra coetanei. In T. Musatti \& S. Mantovani (Orgs.), Stare insieme al nido: relazioni sociali e interventi educativi. Juvenilia.

Fogel, A. (1993). Developing through relationships. Chicago: University Chicago Press.

Franchi e Vasconcelos, C. R., Amorim, K. S., Anjos, A. M. A., \& Rossetti-Ferreira, M. C. (2003). A incompletude como virtude: interação de bebês na creche. Psicologia: Reflexão e Crítica, 16(2), 293-301.

Hinde, R. A. (1997). Relationships: A dialectical perspective. Hove, UK: Psychology Press.

Horowitz, F. D. (1987). Exploring developmental theories: Toward a structural/behavior model of development. Hillsdale, NJ: Lawrence Erlbaum Associates.

Kuhn, T. S. (1962). The structure of scientific revolutions. Chicago: University Press.

Lamb, M. E. (2005). Attachments, social networks and developmental contexts. In M. E. Lewis \& K. Takahashi (Eds.), Beyond the dyad: Conceptualization of social networks. Human Development, 48(1-2), 108-112.

Legendre, A. (1989). Young children's social competences and their use of spaces in day-care centers. In B. H. Schneider (Ed.), Social competence in developmental perspective (pp. 263-276). Dordrecht: Kluwer.

Lewis, M., \& Takahashi, K. (Eds). (2005). Beyond the dyad: Conceptualization of social networks. Human Development, 48(1-2), 5-7.

Lyra, M. C. D. P. (2000). Desenvolvimento de um sistema de relações historicamente construído: contribuições da comunicação no início da vida. Psicologia: Reflexão e Crítica, 13(2), 257-268.

Main, M. (1998). De l'attachment à la psychopathologie. Enfance, 3, 13-27.

Mantovani, S., \& Terzi, N. (1987). L'inserimento. In A. Bondoli \& S. Mantovani (Eds.), Manuale critico dell'asilo nido. Milano: Franco Angeli.

Martins, L. B. (2008). Dez anos de inclusão de pessoas com necessidades especiais, em escolas municipais de ensino regular, de Ribeirão Preto. Monografia de Conclusão de Curso em Pedagogia, Faculdade de Filosofia, Ciências e Letras de Ribeirão Preto, Universidade de São Paulo, Ribeirão Preto, SP.

Maturana, H. (1994). El sentido de lo humano. Santiago: Dolmen.

Maturana, H., \& Varela, F. (1984). El árbol del conocimento: las bases biológicas del entendimiento humano. Santiago: Editorial Universitária.

Mello, A. M. A. (1999). História da Carochinha: uma experiência para a educação de crianças abaixo de 3 anos em creche. Dissertação de Mestrado em Psicologia, Faculdade de Filosofia, Ciências e Letras de Ribeirão Preto, Universidade de São Paulo, Ribeirão Preto, SP.

Morin, E. (1990). Introdução ao pensamento complexo. Lisboa: Epistemologia e Sociedade. 
Mueller, E., \& Lucas, T. (1975). A developmental analysis of peer interaction among toddlers. In M. Lewis \& L. A. Rosenblum (Orgs.), Friendship and peer relations (pp. 223-257). New York: Wiley-Interscience.

Oliveira,Z.M.R.(1988).Jogo depapéis:umaperspectiva para análise do desenvolvimento humano. Tese de Doutorado, Instituto de Psicologia, Universidade de São Paulo, São Paulo.

Oliveira, Z. M. R. (1995). A criança e seu desenvolvimento: perspectivas para discutir a educação infantil. São Paulo: Cortez.

Oliveira, Z. M. R. (2001). The concept of role as unit of analysis of young peers' interactions. In S. Chaiklin (Ed.), The theory and practice of cultural-historical psychology (pp. 124-134). Aarhus, Dinamarca: Aarhus University Press.

Oliveira, Z. M. R. (2002). Creches no sistema de ensino. In M. L. Machado (Org.), Encontros e desencontros em Educação Infantil (pp. 79-82). São Paulo: Cortez.

Paula, E. M. A. T. (1994). Comida, diversão e arte. O coletivo infantil em situação de alimentação na creche. Dissertação de Mestrado em Educação, Faculdade de Educação, Universidade de São Paulo, São Paulo, SP.

Paula, E. M. A. T., \& Oliveira, Z. M. R. (1995). “Comida, diversão e arte": o coletivo infantil no almoço na creche. In Z. Oliveira (Org.), A criança e seu desenvolvimento (pp. 85104). São Paulo: Cortez.

Pino, A. (2003). Processos de significação e constituição do sujeito. Temas de Psicologia, 1, 17-24.

Poster, M. (1979). Teoria crítica da família. Rio de Janeiro: Zahar.

Pramling, I., \& Lindhal, N. (1992). Entering the world of day care. 5th European Conference on Child Development, Sevilha, Espanha. (Trabalho não publicado)

Rayna, S. (1987). Étude de la communication preverbale entre jeunes enfants. Pediatrie, 42(9), 711-714.

Rosemberg, F. (1982). Mãe que é mãe deixa seu filho em creche? Psicologia Atual, 3, 38-42.

Roriz, T. M. (2005). Inclusão/exclusão social e escolar de crianças com paralisia cerebral sob a óptica dos profissionais da saúde. Dissertação de Mestrado em Ciências Médicas, Faculdade de Medicina de Ribeirão Preto, Universidade de São Paulo, Ribeirão Preto, SP.

Roriz, T. M. S., Amorim, K. S., \& Rossetti-Ferreira. (2005). Inclusão social/escolar de pessoas com necessidades especiais: múltiplas perspectivas e controversas práticas discursivas. Psicologia USP, 16(3), 167-194.

Rossetti-Ferreira, M. C. (1988). A pesquisa na universidade e a educação da criança pequena. Cadernos de Pesquisa, 67, 59-63.

Rossetti-Ferreira, M. C. Amorim, K. S., \& Vitória, T. (1994). A creche enquanto contexto possível de desenvolvimento da criança pequena. Revista Brasileira de Crescimento e Desenvolvimento Humano, 4(2), 35-44.

Rossetti-Ferreira, M. C., Amorim, K. S., \& Vitória, T. (1996). Emergência de novos significados durante o processo de adaptação de bebês à creche. Coletâneas da 
ANPPEP, 4(1), 111-143.

Rossetti-Ferreira, M. C. Amorim, K. S., \& Vitória, T. (1997). Integração família e creche - o acolhimento é o princípio de tudo. Estudos em Saúde Mental, Ribeirão Preto, FMRP-USP, 107-131.

Rossetti-Ferreira, M. C., Amorim, K. S., \& Silva, A. P. S. (2000). Uma perspectiva teóricometodológica para análise do desenvolvimento humano e do processo de investigação. Psicologia: Reflexão e Crítica, 13(2), 281-293.

Rossetti-Ferreira, M. C., Amorim, K. S., \& Silva, A. P. S. (2004). Rede de significações: alguns conceitos básicos. In M. C. Rossetti-Ferreira, K. S. Amorim, A. P. S. Silva \& A. M. A. Carvalho (Orgs.), Rede de significações e o estudo do desenvolvimento humano (pp. 23-33). Porto Alegre: Artmed.

Rossetti-Ferreira, M. C., Amorim, K. S., Silva, A. P. S., \& Carvalho, A. M. A. (Orgs.). (2004). Rede de significações e o estudo do desenvolvimento humano. Porto Alegre: Artmed.

Silva, A. P. S. (2003). (Des)continuidade no envolvimento com o crime: construção de identidade narrativa de ex-infratores. São Paulo: IBCCRIM.

Silveira, R. E. S., Rossetti-Ferreira, M. C., Picolo, T. F., Delphino, V. P., \& Faria, L. M. (1987). Oportunidades de contato entre o adulto e as crianças em creches. Revista Brasileira de Estudos Pedagógicos, 168(4), 130-163.

Spink, M. J. P. (Org.). (1999). Práticas discursivas e produção de sentidos no cotidiano. São Paulo: Cortez.

Stambak, M., \& Verba, M. (1986). Organization of some social play among toddlers: An ecological approach. In E. Mueller \& C. R. Cooper (Orgs.), Process and outcome in peer relationships (pp. 229-247). New York: Academic Press.

Wallon, H. (1959a). Os meios, os grupos e a psicogênese da criança. In M. J. G. Werebe \& J. Nadel-Brulfert (Orgs.), Henri Wallon (pp. 168-178). São Paulo: Ática.

Wallon, H. (1959b). O papel do outro na consciência do eu. In M. J. G. Werebe \& J. Nadel-Brulfert (Orgs.), Henri Wallon (pp. 158-167). São Paulo: Ática.

Yazlle, C. H. D. (2000). Pré-escolas convivendo com a paralisia cerebral. Uma análise do processo de inclusão/exclusão. Dissertação de Mestrado em Saúde Mental, Faculdade de Medicina de Ribeirão Preto, Universidade de São Paulo, Ribeirão Preto, SP.

Yazlle, C. H., Amorim, K. S., \& Rossetti-Ferreira, M. C. (2004). A RedSig como recurso metodológico na investigação do processo de inclusão de crianças portadoras de paralisia cerebral na pré-escola. In M. C. Rossetti-Ferreira, K. S. Amorim, A. P. S. Silva \& A. M. A. Carvalho (Orgs.), Rede de significações e o estudo do desenvolvimento humano (Vol. 1, pp. 190-206). Porto Alegre: Artmed. 
Maria Clotilde Rossetti-Ferreira, Professora titular do Departamento de Psicologia e Educação da FFCLRP-USP. Coordenadora do Centro de Investigações sobre Desenvolvimento Humano e Educação Infantil (CINDEDI), FFCLRP-USP.

Katia de Souza Amorim, Departamento de Psicologia e Educação da FFCLRPUSP. Pesquisadora do CINDEDI. Docente do programa de pós-graduação em Psicologia da FFCLRP-USP.

Zilma de Moraes Ramos de Oliveira, Professora associada do Departamento de Psicologia e Educação da FFCLRP-USP. Docente do programa de pósgraduação da FEUSP. Pesquisadora do CINDEDI.

Endereço para correspondência (para as três autoras): CINDEDI - FFCLRP/USP. Av. Bandeirantes, 3900. Ribeirão Preto, São Paulo. CEP 14040-911. Endereço eletrônico: mcrferre@usp.br

Recebido em: 19/02/2009

Aceito em: 18/05/2009 